\section{Musculación. El diseño anatómico y su función}

Por Everet Aaberg

Madrid: Ediciones Tutor, 2006

232 páginas. $21,5 \times 27,8 \mathrm{~cm}$. Ilustraciones

I.S.B.N.: 84-7902-596-0 • 25,00€

Disponible en:

Ediciones Tutor

C/ Marqués de Urquijo, 34, $2^{\circ}$ Izda

28008 Madrid (España)

Telf.: +34915599832

Fax: +34915410235

E-mail: info@edicionestutor.com

http//www.edicionestutor.com

\section{Revisión por Gonzalo Cuadrado Sáez}

El libro que llega ahora a mis manos con el título de Musculación. El diseño anatómico y su función, fue publicado en EE. UU. Por Human Kinetics Publishers, Inc. con el título Muscle Mechanics y ha sido publicado en España por Ediciones TUTOR S.A. Viene este comentario para poner de manifiesto que es una traducción de un original, lo que puede ser la causa del posible error que se encuentra en su portada. Debajo del título en español aparece la frase "La técnica correcta de 65 ejercicios para el entrenamiento de la resistencia". Lo mismo sucede en la descripción que hacen del autor en la que le definen como experto en el entrenamiento de la resistencia. Estoy observando últimamente que en las traducciones de libros que versan sobre el trabajo de la fuerza, se está traduciendo la frase "entrenamiento contra resistencias" como entrenamiento de la resistencia, lo que puede inducir a error a las personas que, sin entrar en el interior del libro, desestimen su lectura por no ser lo que buscan, o al contrario que le adquieran y luego no les sirva para sus objetivos.

Entrando directamente en el comentario del texto que hoy nos incumbe, podemos decir que es una obra que une varias cosas que la hacen muy interesante para aquellas personas aficionadas al trabajo de fuerza.

Empieza con un primer capítulo en el que se hace un estudio sobre el aparato motor, tanto sobre el sistema pasivo, el esqueleto, con una descripción de los núcleos articulares y sus posibilidades de movimiento, como del sistema activo, músculos y tendones, de los que va mostrando sus funciones en cada uno de los movimientos anteriormente referidos. Termina este capítulo con lo que el autor llama el sistema de control, sistemas nerviosos central y periférico y los distintos receptores sensoriales encargados de proporcionar información al SNC y que es de gran importancia en la ejecución técnica de los movimientos.

En el segundo capítulo muestra cómo se ha de hacer la selección de los ejercicios y nos propone los cuatro pasos que implica dicha selección: Establecimiento de las metas, centrarse en el movimiento deseado, centrarse en los grupos musculares deseados y el análisis del beneficio riesgo

El trabajo con sobrecargas puede representar un riesgo si no se hacen los ejercicios de la forma adecuada, evitar ese riesgo y conseguir los objetivos pretendidos es el objetivo del autor en el tercer capítulo. El tipo y trayectoria de los movimientos, el rango, la colocación, el ritmo y la estabilidad, son conceptos que el autor desmenuza para ayudar a un buen trabajo.

En los capítulos cuarto al octavo, se hace una perfecta descripción de un amplio repertorio de ejercicios para el trabajo de musculación de todos los segmentos corporales incluyendo por una parte todos los fundamentos teóricos necesarios para la buena comprensión y ejecución por parte del lector, así como fotografías que, además de demostrar gráficamente la forma del ejercicio, superponen los grupos musculares que intervienen en él haciendo muy sencillo su uso.

El capítulo final nos muestra cómo se puede diseñar un programa de entrenamiento para el trabajo de la fuerza y a utilizar de manera eficiente los componentes de la carga del entrenamiento.

En resumen se trata de un buen libro que quede ayudar a personas no expertas a iniciarse en el trabajo de la fuerza

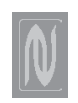

\section{El legado espiritual del templo Shaolin: el budismo, taoísmo y las artes energéticas}

Por Andy James

Móstoles: Arkano Books, 2005

256 páginas. $15 \times 21 \mathrm{~cm}$. Ilustraciones

I.S.B.N.: 84-96111-17-2 • 12,00€

\section{Disponible en:}

Distribuciones y Ediciones Alfaomega

C/ Alquimia, 6. P.I. Los Rosales

28933 Móstoles, Madrid (España)

Telf.: +34916179714

Fax: +34916179714

E-mail: editorial@alfaomega.es

http://www.alfaomega.es/

\section{Revisión por Héctor P. Fariña López}

Este libro se estructura en tres partes. En la primera plantea, ya desde el prefacio, lo que ha motivado la elaboración de la obra, refiriéndose a cómo ha calado a lo largo de los últimos 30 años la imagen de Shaolin. El autor, después de pensar que el conocimiento de Shaolín beneficiaría el acercamiento de occidente a las "tradiciones orientales", constata que las inexactitudes y el falso conocimiento han producido un efecto negativo. No obstante, Andy James es de los que opinan que occidente necesita una transformación personal y colectiva, y ve en estas tradiciones orientales un camino para hacerlo.

Esta primera parte termina de forma autobiográfica, para mostrar cómo ha llegado el autor a esa búsqueda, ofreciendo algunas reflexiones personales de interés, aunque en ocasiones se extiende en detalles poco útiles y aparece la primera sorpresa: el autor prácticamente no ha tenido contacto con el Arte del Shaolin.

La segunda parte entra en el tema principal: "el legado espiritual de Shaolin", desarrollando cómo ha influido el Templo y sus prácticas desde Bodhidarma y su época de más desarrollo, el período Tang, en la aparición de ese nuevo concepto del "guerrero espiritual" que reconoce que la batalla espiritual es interior y exterior, que no desprecia al mundo, ni a su salud física, ni tan siquiera las artes de combate.

A continuación sigue un desarrollo de las diferentes filosofías imperantes en China y cómo fueron influenciándose, además de prácticas hindúes que muchas veces se 